\title{
Retrospective analysis of total direct medical costs associated with hepatitis B patients with oral antiviral versus pegylated interferon therapy in Turkey
}

\author{
A. Altinbas, ${ }^{1}$ E. Baser, ${ }^{2}$ A. Burkan, ${ }^{3}$ E. Ertugay, ${ }^{3}$ M. F. Kariburyo ${ }^{4}$ and O. Baser ${ }^{5}{ }^{1}$ Ankara Numune \\ Education and Research Hospital, Gastroenterology Clinic, Ankara, Turkey; ${ }^{2}$ STATinMED Research, Ankara, Turkey; ${ }^{3}$ Social Security Institution, \\ Ankara, Turkey; ${ }^{4}$ STATinMED Research, Ann Arbor, MI, USA; and ${ }^{5}$ The University of Michigan and STATinMED Research, Ann Arbor, MI, \\ USA
}

Received June 2013; accepted for publication September 2013

SUMMARY. To explore healthcare costs associated with antiviral treatment of hepatitis B virus (HBV) in Turkey. Research-identified data from a claims processing system for all Turkish health insurance funds were analysed. Adult patients prescribed oral antiviral and pegylated interferon treatment were identified between 1 January 2010 and 31 December 2010. The first prescription date was defined as the index date. Patients were required to have HBV diagnosis within the 6-month pre-index period. Pharmacy, outpatient and inpatient claims were compiled over the study period for the selected patients, and riskadjusted 1-year healthcare costs of patients with oral antiviral and pegylated interferon treatment were compared. Risk adjustment was carried out using propensity score matching, controlling for baseline demographic and clinical characteristics. A total of 9618 patients were identified, of which 9074 were treated with oral antiviral medication and 544 with pegylated interferon medication. The oral antiviral treatment group was older $(45.28$ vs 42.19 , $P<0.001)$, less likely to be female $(32.17 \%$ vs $39.71 \%$, $P<0.001)$ and to reside in Southeastern Anatolia $(8.29 \%$ vs $13.97 \%, P<0.001)$ or Mediterranean region $(8.90 \%$ vs $11.76 \%, P<0.03)$ and had higher Elixhauser comorbidity index scores $(60.22 \%$ vs $74.08 \%, P<0.001)$ than the pegylated interferon group. After adjusting for confounding factors, total medical costs for pegylated interferon patients were $€ 2771$ higher than for oral antiviral patients $(P<0.001)$, due to higher outpatient and prescription costs. For annual healthcare costs for antiviral treatment options for HBV patients in Turkey, after adjusting for age, gender, region and comorbid condition differences, oral antiviral treatment is more costly than pegylated interferon treatment.

Keywords: hepatitis b, medical costs, outcomes research, real-word data analysis.

\section{INTRODUCTION}

Hepatitis B virus (HBV) is a major global health problem. According to 2009 World Health Organization (WHO) estimates, $>2$ billion people have been exposed to HBV [1]. 378 million are chronically infected worldwide [2].

Abbreviations: AHRQ, Agency for Healthcare Research and Quality; CHB, chronic hepatitis B; FFS, fee-for-service; GLMs, generalized linear models; HBsAg, hepatitis B surface antigen; HBV, hepatitis B virus; HCC, hepatocellular carcinoma; PSM, propensity score matching; SSI, Social Security Institute; UHI, Universal Health Insurance.

Correspondence: Onur Baser, MS, PhD, Adjunct Professor, Internal Medicine, Rheumatology Division, The University of Michigan, President \& CEO, STATinMED Research, 211 North 4th Avenue, Suite 2B, Ann Arbor, MI 48104, USA.

E-mail: onur@med.umich.edu
Approximately 600000 deaths each year are associated with acute and chronic consequences of hepatitis B. HBV infection is the leading cause of chronic hepatitis and cirrhosis worldwide, and approximately $40 \%$ of all chronic hepatitis $\mathrm{B}(\mathrm{CHB})$ patients will develop cirrhosis, liver failure or hepatocellular carcinoma (HCC) [3].

According to WHO classification, Turkey is an intermediate $(2-8 \%)$ endemic country for HBV seropositivity, with varying rates from west to east regions (from $2-4 \%$ to $3.9-$ $12.5 \%$, respectively) [4-6]. In intermediate endemic areas, the most common routes of HBV transmission are believed to be mother-to-child and horizontal transmission via close contact [5]. According to the Ministry of Health report of 2003 in Turkey, almost one-third of the population in Turkey has already been infected with $\mathrm{HBV}$; 3-4 million are carriers and nearly 350 cases of HCC have been reported [7].

The natural course of HBV infection has a great spectrum from a chronic carrier state, chronic active hepatitis 
and cirrhosis, after acute exposure [8]. The possibility of chronic HBV infection is higher for newborns, in whom the exposure occurs during pregnancy or delivery, and the lowest is for adults. Most acute HBV infections lead to spontaneous hepatitis B surface antigen (HBsAg; a marker of communicability) clearance in adults [9].

In 1998, a national vaccination programme was launched to prevent prenatal transmission of HBV in Turkey. The prevalence of HBsAg positivity has dropped from $4.19 \%$ to $2.10 \%$, with the help of the programme $[4,10]$. However, the economic burden of $\mathrm{HBV}$ is substantial because of the long-term effects of HBV infection on the liver. Over $\$ 1$ billion is spent annually for HBV-related hospitalizations [11]. For instance, in the United States, the trend in economic burden reflects a considerable increase in the last decade [12], with estimated HBV-related hospitalization costs increasing from $\$ 357$ million in 1990 to $\$ 1.5$ billion in 2003 [12]. The primary reasons for the rise in HBV-related healthcare costs are increased outpatient visits and hospitalizations, more expensive diagnostic tools and new therapeutic options for HBV-positive patients. Akarsu et al. [13] evaluated the relationship between aetiological groups and costs and determined that the highest costs were incurred among HBV and HCC patients with 75\% HBV-positivity.

Significant progress has been made in antiviral HBV treatment, capable of effectively suppressing viral replication in $95 \%$ of cases of $\mathrm{CHB}$ [14]. The main goals of HBV treatment are to prevent cirrhosis, hepatic decomposition and HCC, thereby improving mortality and morbidity rates and quality of life by preventing disease progression [14]. Two available treatment approaches consist of either stimulating the immune system through pegylated interferon or suppressing viral load through nucleotide analogues (lamivudine, adefovir, entecavir, telbivudine and tenofovir) [14,15]. It has been well documented that oral antiviral drugs are generally better tolerated and suppress HBV viral load more effectively than pegylated interferon therapy, but must have longer duration of use [16]. Therefore, in this study using national claims data, comparative effectiveness research was designed to inform healthcare decision-makers by providing evidence of total healthcare costs of $\mathrm{HBV}$ patients who were prescribed oral antiviral and pegylated interferon therapy.

\section{MATERIALS AND METHODS}

In 2006, Turkey began a social security and health system under the Social Security Institute (SSI). Mandatory enrolment is required for the current Universal Health Insurance (UHI) Fund within the SSI. Insurance contribution rates are determined proportionally to a patient's ability to pay, and all beneficiaries are entitled to the same benefit package.
In Turkey, payment by health insurance fund is based both on a retrospective fee-for-service (FFS) and bundled payment system, depending on disease category and services related to the particular disease. Payment procedures are outlined by health budget laws (Sağlı Uygulama Tebliği or SÜT). University hospitals are paid based on the FFS system. Private hospitals, however, are generally paid according to the bundled payment system. Laboratory services can be paid separately through the bundled payment system, based on certain conditions. Access to $\mathrm{CHB}$ drugs is determined by Ministry of Health protocol, and payment is determined by the health budget laws of the SSI. These protocols and health budget laws describe under what conditions, how much and which patients should be prescribed these medications.

Data for this study were obtained from MEDULA, a nationwide medical information collection system in Turkey, which was established under the 2007 Health Budget Law. The research-identified MEDULA data set is comprised of pharmacy, inpatient, outpatient and laboratory claims and encompasses 17800 pharmacies, 5600 general practitioners, 4500 medical centres, 1200 government hospitals and 338 private hospitals, covering more than $80 \%$ of the population in Turkey. The remaining 20\% of the population not included in the data consists of those whose contribution rates were paid by the government due to their income level. These data were maintained separately from the UHI Fund in the SSI until 2012. Moreover, members of the Turkish Grand National Assembly and the Supreme Court as well as foreign insurance holders and some military personnel were excluded from the UHI Fund in the SSI. The data have been used in several outcomes research studies [17-21].

In this retrospective analysis, the study period was from 1 July 2009 through 31 December 2011. Oral antiviral and pegylated interferon therapy use during the identification period (1 January 2010-31 December 2011) was first identified. The first prescription date was designated as the index date. All patients were required to be continuously enrolled during the 6-month pre-index (baseline) period and 12-month postindex (follow-up) period. Using appropriate diagnosis codes from the International Classification of Diseases Tenth Revision Clinical Modification (ICD-10$\mathrm{CM}$ ), all patients with chronic or active HBV in the preindex period were included in the study. Patients under 18 years of age, who were pregnant, diagnosed with human immunodeficiency virus (HIV) infection, underwent immunosuppressive or cancer therapy, had history of cirrhosis or chronic liver failure, hepatitis $\mathrm{C}$ or delta hepatitis during the 6-month pre- and 12-month postindex periods were excluded from the analysis (Fig. 1).

Demographic factors such age, gender and region were available in the data. To control for clinical characteristics, we calculated a comorbidity index score for each patient for the baseline period, using the Elixhauser method [22]. The index has been widely used, because it differentiates 


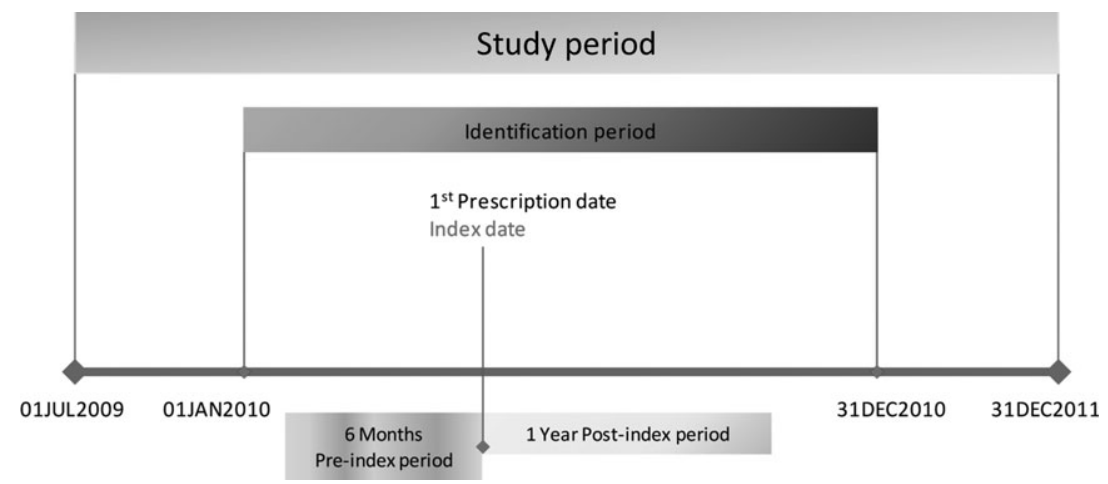

Fig. 1 Description of study period.

comorbid complications by excluding the codes that reflect acute conditions. For example, pneumonia, pleural effusion, urinary tract infection, cardiac arrest, cardiogenic shock and respiratory failure were not counted as comorbidities because they are not distinguishable from complications that may have resulted from diagnostic or therapeutic interventions during hospitalization. Comorbidities such as benign prostatic hypertrophy, inguinal hernia and diverticulitis were not included, because they do not impact resource use or mortality if they were not principle diagnosis. Current coding for the Elixhauser index is available from the Agency for Healthcare Research and Quality (AHRQ) [23]. Individual comorbidities such as essential hypertension, type 2 diabetes and atherosclerotic heart disease of native coronary artery were also identified.

Reimbursement amounts were available in the data, and the annual costs were separated by inpatient, outpatient and pharmacy costs and copays.

Causal inference is challenging in all nonexperimental studies because of the possibility of overt bias. When evaluating certain treatment groups, overt bias can occur as treatment and control groups differ in terms of observable factors such as age, gender, region and comorbidities. To eliminate overt bias in the current study, propensity score matching (PSM) was applied to compare healthcare costs associated with oral antiviral and pegylated interferon use. PSM employs the predicted probability of group membership and isolates the observed bias from the estimation [24]. Specifically, a patient's propensity score is the probability of being treated based on the condition of the patient's covariate values, such as demographic and clinical factors. If two patients, one in the oral antiviral and the other in the pegylated interferon group, with the same or similar propensity score, these subjects can be considered similar for all observed factors that are controlled to predict probability. The only difference is that one patient used oral antiviral treatment and the other pegylated interferon. Consequently, all outcomes (costs, utilization) of the matched group are due to treatment only and not other factors, such as age, gender and comorbiditiesc. Following the guidelines to choose the most appropriate matching technique for study data, radius, kernel, mahalanobis and one-to-one matching were compared and ultimately one-to-one matching was applied [25]. Patient age, gender, region, Elixhauser index score and baseline individual comorbidities were used as explanatory variables in the PSM model.

The analysis was conducted using SAS V.9.3 (SAS Institute Inc., Cary, NC, USA) and STATA V11 software (StataCorp LP, College Station, TX, USA).

\section{RESULTS}

A total of 9074 patients in the oral antiviral group and 544 in the pegylated interferon group satisfied all inclusion and exclusion criteria (Fig. 2) and were included in the study population.

Patients in the oral antiviral group were older (45.28 vs 42.19, $P<0.001)$, less likely to be female $(32.17 \%$ vs $39.71 \%, P<0.001)$ and reside in the Southeastern Anatolia $(8.29 \%$ vs $13.97 \%, P<0.001)$ or Mediterranean regions ( $8.90 \%$ vs $11.76 \%, P<0.030$ ), relative to those in the pegylated interferon group. Patients prescribed pegylated interferon medication had higher Elixhauser comorbidity index scores than those prescribed oral antiviral medications $(60.22 \%$ vs $74.08 \%, P<0.001)$. There were no significant differences in individual comorbid conditions such as hypertension, diabetes and heart disease between the two groups (Table 1).

The primary objective was to compare total healthcare costs between HBV patients prescribed oral antiviral and pegylated interferon medications. Because descriptive comparison of costs would be confounded by the differences in age, gender, region and comorbidity index scores, as outlined in the previous paragraph, PSM was employed.

Table 2 presents the results after PSM. A total of 544 patients in the pegylated interferon group were matched with comparable patients in the oral antiviral group in terms of age, gender, region, comorbidity index score and individual comorbidities. As presented in $P$-values in Table 2, after matching, there were no significant differences in the observed baseline characteristics.

Over the matched sample, annual healthcare costs after medication use between the two groups were calculated 


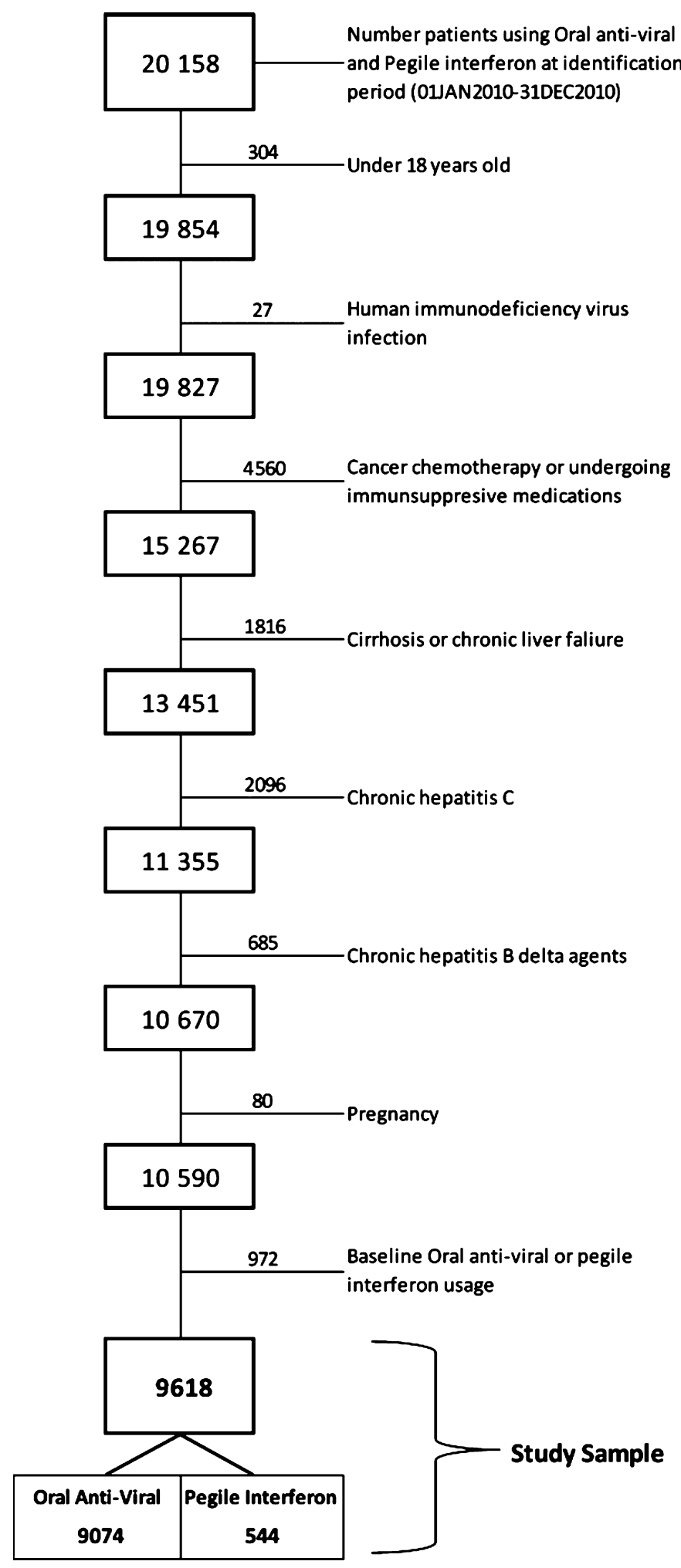

Fig. 2 Inclusion and exclusion criteria of the HBV patient study sample.

and compared. This risk-adjusted comparison isolates the differences in terms of the demographic and clinical characteristics outlined in Tables 1 and 2 .
Annual risk-adjusted total medical costs for patients with pegylated interferon use were €5729. Costs were significantly higher than for patients prescribed oral antiviral 
Table 1 Oral antiviral vs pegylated interferon use

\begin{tabular}{|c|c|c|c|c|c|}
\hline & \multicolumn{2}{|c|}{$\begin{array}{l}\text { Oral antiviral } \\
\text { patients } N=9074\end{array}$} & \multicolumn{2}{|c|}{$\begin{array}{l}\text { Pegylated interferon } \\
\text { patients } N=544\end{array}$} & \multirow[b]{2}{*}{$P$-value } \\
\hline & Mean $(N)$ & $\mathrm{SD}(\%)$ & Mean $(N)$ & $\mathrm{SD}(\%)$ & \\
\hline Age & 45.28 & 13.06 & 42.19 & 13.33 & $<.0001$ \\
\hline $18-35$ & 2216 & 24.42 & 189 & 34.74 & $<.0001$ \\
\hline $36-45$ & 2316 & 25.52 & 121 & 22.24 & 0.0875 \\
\hline $46-55$ & 2524 & 27.82 & 144 & 26.47 & 0.4961 \\
\hline $56-65$ & 1460 & 16.09 & 70 & 12.87 & 0.0459 \\
\hline $66+$ & 558 & 6.15 & 20 & 3.68 & 0.0184 \\
\hline Female & 2919 & 32.17 & 216 & 39.71 & 0.0003 \\
\hline \multicolumn{6}{|l|}{ Region } \\
\hline East Anatolia & 1170 & 12.89 & 69 & 12.68 & 0.8870 \\
\hline Southeastern Anatolia & 752 & 8.29 & 76 & 13.97 & $<.0001$ \\
\hline Marmara & 1547 & 17.05 & 89 & 16.36 & 0.6781 \\
\hline Aegean & 983 & 10.83 & 45 & 8.27 & 0.0604 \\
\hline Mediterranean & 808 & 8.90 & 64 & 11.76 & 0.0240 \\
\hline Black Sea & 1943 & 21.41 & 101 & 18.57 & 0.1149 \\
\hline Central Anatolia & 1871 & 20.62 & 100 & 18.38 & 0.2093 \\
\hline \multicolumn{6}{|l|}{ Elixhauser Index Score } \\
\hline$>2$ & 5464 & 60.22 & 403 & 74.08 & $<.0001$ \\
\hline \multicolumn{6}{|l|}{ Baseline diagnosis } \\
\hline Essential hypertension (Primary) & 1297 & 14.29 & 72 & 13.24 & 0.4926 \\
\hline Type 2 diabetes mellitus & 341 & 3.76 & 18 & 3.31 & 0.5914 \\
\hline Atherosclerotic heart disease of native coronary artery & 155 & 1.71 & 15 & 2.76 & 0.0713 \\
\hline
\end{tabular}

$\mathrm{SD}=$ standard deviation.

medications $(€ 2958, P<0.001)$. Although there were no significant differences between inpatient costs and copays, outpatient ( $€ 588$ vs $€ 334, P<0.001$ ) and pharmacy costs (€2554 vs €4965, $P<0.001$ ) were significantly higher for patients with pegylated interferon use vs oral antiviral use (Table 3).

\section{DISCUSSION}

Comparative effectiveness data determine trade-offs driven by different cost profiles among treatment options, and secondary databases provide a valuable source of information for healthcare solutions.

The current study, using national health insurance data in Turkey, compared the annual costs of HBV patients prescribed oral antiviral and pegylated interferon therapy. Although oral antiviral drugs were better tolerated and suppressed HBV viral load values more effectively, longer duration of use relative to pegylated interferon therapy created ambiguous cost-effectiveness results. There are most likely two main reasons why oral antiviral drugs are less expensive. First, there are only two medications that consisted of pegylated interferon in our study, and the number of marketed oral antiviral agents is five with perhaps three to four times as many generic agents available in Turkey.
Second, the technologies used to produce interferon and oral antiviral agents are quite different. It is probably more difficult and expensive to produce interferon.

Previously, in a cost-effectiveness analysis of CHB treatment in Turkey, Toy et al. [3] reported that annual costs of pegylated interferon alfa-2a were €9624 compared with lamivudine (€585), adefovir (€5976), entecavir (€5618) and tenofovir (€3994). However, this study was based on Markov cohort analysis using a database of two reference hospitals in Ankara, Turkey. The natural history of chronic HBV patients was assessed based on data from western countries. Due to sample size issues, individual treatment effects among prescribed oral antiviral medications were not examined. Previous studies showed that treatment is cost-effective vs no treatment [26-30].

To ensure that economic evaluations are relevant, country-specific observational studies are necessary. Real-world data analysis provides information about real-world clinical practices across patient subgroups, which is difficult to assess from trials, surveys, expert opinions and individual hospital data. Recognizing the importance of real-world data, Turkey invested in stronger information technology systems. MEDULA, a nationwide integrated claims and utilization management system, is the outcome of the investment. The use of the MEDULA data set allows researchers 
Table 2 Oral antiviral vs pegylated interferon use (matched)

\begin{tabular}{|c|c|c|c|c|c|}
\hline & \multicolumn{2}{|c|}{$\begin{array}{l}\text { Oral antiviral } \\
\text { patients } N=544\end{array}$} & \multicolumn{2}{|c|}{$\begin{array}{l}\text { Pegylated interferon } \\
\text { patients } N=544\end{array}$} & \multirow[b]{2}{*}{$P$-value } \\
\hline & Mean $(N)$ & $\mathrm{SD}(\%)$ & Mean $(N)$ & $\mathrm{SD}(\%)$ & \\
\hline Age & 41.74 & 13.24 & 42.19 & 13.33 & 0.5762 \\
\hline $18-35$ & 193 & 35.48 & 189 & 34.74 & 0.7994 \\
\hline $36-45$ & 130 & 23.90 & 121 & 22.24 & 0.5172 \\
\hline $46-55$ & 139 & 25.55 & 144 & 26.47 & 0.7297 \\
\hline $56-65$ & 59 & 10.85 & 70 & 12.87 & 0.3023 \\
\hline $66+$ & 23 & 4.23 & 20 & 3.68 & 0.6406 \\
\hline Female & 201 & 36.95 & 216 & 39.71 & 0.3496 \\
\hline \multicolumn{6}{|l|}{ Region } \\
\hline East Anatolia & 72 & 13.24 & 69 & 12.68 & 0.7865 \\
\hline Southeastern Anatolia & 71 & 13.05 & 76 & 13.97 & 0.6575 \\
\hline Marmara & 83 & 15.26 & 89 & 16.36 & 0.6181 \\
\hline Aegean & 47 & 8.64 & 45 & 8.27 & 0.8275 \\
\hline Mediterranean & 67 & 12.32 & 64 & 11.76 & 0.7799 \\
\hline Black Sea & 104 & 19.12 & 101 & 18.57 & 0.8161 \\
\hline Central Anatolia & 100 & 18.38 & 100 & 18.38 & 1.0000 \\
\hline \multicolumn{6}{|l|}{ Elixhauser Index Score } \\
\hline$\leq 2$ & 130 & 23.90 & 141 & 25.92 & 0.4406 \\
\hline$>2$ & 414 & 76.10 & 403 & 74.08 & 0.4406 \\
\hline \multicolumn{6}{|l|}{ Baseline diagnosis } \\
\hline Essential (primary) hypertension & 64 & 11.76 & 72 & 13.24 & 0.4633 \\
\hline Type 2 diabetes mellitus & 16 & 2.94 & 18 & 3.31 & 0.7275 \\
\hline Atherosclerotic heart disease of native coronary artery & 9 & 1.65 & 15 & 2.76 & 0.2155 \\
\hline
\end{tabular}

$\mathrm{SD}=$ standard deviation

Table 3 Risk-adjusted healthcare costs

\begin{tabular}{|c|c|c|c|c|c|}
\hline \multirow[b]{2}{*}{ Follow-up healthcare costs } & \multicolumn{2}{|c|}{$\begin{array}{l}\text { Oral antiviral patients } \\
N=550\end{array}$} & \multicolumn{2}{|c|}{$\begin{array}{l}\text { Pegylated interferon patients } \\
N=550\end{array}$} & \multirow[b]{2}{*}{$P$-value } \\
\hline & Mean & SD & Mean & SD & \\
\hline Inpatient & $€ 58.93$ & $€ 304.94$ & $€ 162.53$ & $€ 1278.07$ & 0.0664 \\
\hline Outpatient & $€ 334.89$ & $€ 255.59$ & $€ 588.86$ & $€ 1307.13$ & $<0.0001$ \\
\hline Pharmacy & $€ 2554.74$ & $€ 1617.89$ & $€ 4965.90$ & $€ 2556.66$ & $<0.0001$ \\
\hline Copays & $€ 10.23$ & $€ 11.65$ & $€ 11.86$ & $€ 18.76$ & 0.0863 \\
\hline Total costs & $€ 2958.80$ & $€ 1724.09$ & $€ 5729.16$ & $€ 3434.98$ & $<0.0001$ \\
\hline
\end{tabular}

to draw substantial knowledge regarding accurate results of the total economic burden of HBV treatment on the healthcare system in Turkey.

Although the economic burden of HBV has been increasingly recognized, there are a limited number of studies comparing costs associated with pegylated interferon therapies and oral nucleotide analogue HBV medications for European populations. However, in a cost-effectiveness analysis of $\mathrm{CHB}$ in the United Kingdom [31], treatment with pegylated interferon 2 a compared to lamivudine was found to provide improvement in health outcomes and resulted in higher total healthcare costs (£3100).
Sensitivity analysis was performed to determine how the study results would change if regression analysis was applied instead of PSM. As costs were skewed, generalized linear models (GLMs) with log link and gamma distribution were applied. The results were no different from the PSM analysis $(P=0.543)$.

The current study provides baseline data to evaluate the economic effects of such treatments and assist future CHB-related policy and analyses.

This study has several limitations. Claims data are generally collected for payment rather than research purposes. Therefore, the presence of a diagnosis code on a medical 
claim is not necessarily proof of the presence of disease. Diagnoses may be incorrectly coded or included as a rule out criteria rather than actual disease. To mitigate some of the problems associated with ICD-10-CM codes, detailed quality checks were applied, requiring the use of medication with ICD-10-CM diagnosis codes. Secondly, the occurrence of a drug prescription fill does not guarantee the actual consumption of the drug by the patient. Therefore, study results are biased to the extent that adherence to medication is unevenly distributed among treatment options. Although PSM was used to control for risk factors, the data did not contain any measure of disease activity, health status or patient lifestyle. Further studies that can link outcomes measures with clinical severity variables are warranted.

In conclusion, despite the availability of a safe and effective vaccine, CHB remains a public health concern in Turkey, and little is known about the economic burden of CHB in the country. This study is the first to provide data representative of almost the entire Turkish population, and the results reveal that oral antiviral treatment is cost-effective relative to pegylated interferon treatment. Using realworld information, the current study provides valuable information for policymakers to improve healthcare policy in the future.

\section{ACKNOWLEDGEMENTS}

Editorial support was provided by Elizabeth M. Moran of STATinMED Research, Ann Arbor, MI, USA.

\section{COMPETING INTERESTS}

The authors declare they have no competing interests.

\section{AUTHORS' CONTRIBUTIONS}

OB had full access to all of the data in the study and take responsibility for the integrity of the data and the accuracy of the analysis. Study concept and design were carried out by $\mathrm{AA}$ and $\mathrm{OB}$. Acquisition of data was made by $\mathrm{AB}$ and EE. Analysis and interpretation of the data were carried out by $\mathrm{OB}, \mathrm{AA}$ and $\mathrm{EB}$. AA and OB drafted the paper. MFK and AA provided literature research. AA, AB, EB, EE, MFK, OB made critical revisions to the manuscript for important intellectual content. Statistical programming was conducted by $\mathrm{EB}$ and $\mathrm{OB}$. Administrative, technical and material support was provided by $\mathrm{OB}$. OB was responsible for the study supervision. All authors have read and approved the final manuscript.

\section{REFERENCES}

1 Hepatitis B: Fact Sheet No: 204, 2012. Available at: http://www who.int/mediacentre/factsheets/ fs204/en/ (accessed 28 May 2012).

2 Toy M, Veldhuijzen IK, de Man RA, Richardus JH, Schalm SW. Potential impact of long-term nucleoside therapy on the mortality and morbidity of active chronic hepatitis B. Hepatology 2009; 50: 743-751.

3 Toy M, Onder FO, Idilman R et al. The cost-effectiveness of treating chronic hepatitis $\mathrm{B}$ patients in a median endemic and middle income country. Eur J Health Econ 2012; 13: 663-676.

4 Gurol E, Saban C, Oral O, Cigdem A, Armagan A. Trends in hepatitis B and hepatitis $\mathrm{C}$ virus among blood donors over 16 years in Turkey. Eur J Epidemiol 2006; 21: 299-305.

5 Degertekin H, Gunes G. Horizontal transmission of hepatitis $\mathrm{B}$ virus in Turkey. Public Health 2008; 122 (12): 1315-1317.

6 Altınbas S, Erdogan M, Danışman $\mathrm{N}$. The seroprevalences of $\mathrm{HBs} \mathrm{Ag}$ and anti-HCV in pregnant women in Ankara. Arch Gynecol Obstet 2010; 281(2): 371.
7 Hepatitis B in Turkey. Ministry of Health, Turkey, 2013. Available at: http://www.vhpb.org/files/html/Meet ings_and_publications/VHPB_Meet ings/Kyiv2004/pdf/S41enUsta.pdf (accessed 29 May 2013).

8 Marcellin P, Castelnau C, MartinotPeignoux M, Boyer N. Natural history of hepatitis B. Minerva Gastroenterol Dietol 2005; 51(1): 63-75.

9 Altinbas A, Yuksel I, Pamukcu M, Ekiz F, Basar O, Yuksel O. Spontaneous HBsAg seroconversion after severe flare of chronic hepatitis B infection. Ann Hepatol 2010; 9(2): 194-197.

10 Ergunay K, Balaban Y, Cosgun E et al. Epidemiologic trends in $\mathrm{HBV}$ infections at a reference centre in Turkey: an 11-year retrospective analysis. Ann Hepatol 2012; 11(5): 672-678

11 Ozer A, Yakupogullari Y, Beytur A, Beytur L, Koroglu M. Risk factors of hepatitis B virus infection in turkey: a population-based, case-control study: risk factors for HBV infection. Hepat Mon 2011; 11(4): 263-268.

12 Kim W. Epidemiology of hepatitis B in the United States. Hepatology 2009; 49: S28-S34.
13 Akarsu M, Matur M, Karademir S, Unek T, Astarcioglu I. Cost analysis of liver transplantation in Turkey. Transplant Proc 2011; 43(10): 3783-3788.

14 Hatzakis A, Wait S, Bruix J et al. The state of hepatitis B and C in Europe: report from the hepatitis B and C summit conference*. J Viral Hepat 2011; 18(Suppl 1): 1-16.

15 Chien RN, Liaw YF. Nucleos(t)ide analogues for hepatitis B virus: strategies for long-term success. Best Pract Res Clin Gastroenterol 2008; 22(6): 1081-1092.

16 Lau DT, Bleibel W. Review: current status of antiviral therapy for hepatitis B. Therap Adv Gastroenterol 2008; 1(1): 61-75.

17 Baser O, Burkan A, Baser E, Koselerli R, Ertugay E, Altinbas A. Direct medical costs associated with rheumatoid arthritis in Turkey: analysis from National Claims Database. Rheumatol Int 2013; 33 (10): 2577-2584.

18 Baser O, Baser E, Altinbas A, Burkan A. Severity index for rheumatoid arthritis and its association with health care costs and biologic 
therapy use in Turkey. Health Econ Rev 2013; 3(1): 5.

19 Baser O, Burkan A, Baser E, Koselerli R, Ertugay E, Altinbas A. High cost patients for cardiac surgery and hospital quality in Turkey. Health Policy 2013; 109(2): 143-149. Epub 2012 Oct 22.

20 Baser O, Burkan A, Baser E, Koselerli R, Ertugay E, Altinbas A. Health care costs associated with ankylosing spondylitis in Turkey: an analysis from nationwide real-world data. Int J Rheumatol 2013; 2013: 139608. Epub 2013 Feb 19.

21 Baser O, Burkan A, Baser E, Koselerli R, Ertugay E, Altinbas A. Coronary angiography utilization and costs for coronary artery bypass graft surgery patients in Turkey. Cardiol Ther 2013; 2(2): doi: 10. 1007/s40119-013-0018-z

22 Elixhauser A, Steiner C, Harris DR, Coffey RM. Comorbidity measures for use with administrative data. Med Care 1998; 36: 8-27.
23 Baser O, Palmer L, Stephenson J. The estimation power of alternative comorbidity indices. Value Health 2008; 11: 946-955.

24 Rubin DB. Estimating causal effects from large data sets using propensity scores. Ann Intern Med 1997; 127(8 pt 2): 757-763.

25 Baser O. Too much ado about propensity score models? Comparing methods of propensity score matching. Value Health 2006; 9: 377-385.

26 Kanwal F, Gralnek IM, Martin P, Dulai GS, Farid M, Spiegel BM. Treatment alternatives for chronic hepatitis B virus infection: a costeffectiveness analysis. Ann Intern Med 2005; 142(10): 821-831.

27 Kanwal F, Farid M, Martin P et al. Treatment alternatives for hepatitis B cirrhosis: a cost-effectiveness analysis. Am J Gastroenterol 2006; 101(9): 2076-2089.

28 Wong JB, Koff RS, Tinè F, Pauker SG. Cost-effectiveness of interferonalpha $2 \mathrm{~b}$ treatment for hepatitis B e antigen-positive chronic hepatitis B. Ann Intern Med 1995; 122(9): 664-675.

29 Shepherd J, Jones J, Takeda A, Davidson P, Price A. Review Adefovir dipivoxil and pegylated interferon alfa-2a for the treatment of chronic hepatitis B: a systematic review and economic evaluation. Health Technol Assess 2006; 10(28): iii-iv, xi-xiv, 1-183.

30 Buti M, Brosa M, Casado MA, Rueda M. Esteban R Modeling the costeffectiveness of different oral antiviral therapies in patients with chronic hepatitis B. J Hepatol 2009; 51(4): 640-646.

31 Veenstra DL, Sullivan SD, Dusheiko GM et al. Cost-effectiveness of peginterferon alpha-2a compared with lamivudine treatment in patients with HBe-antigen-positive chronic hepatitis B in the United Kingdom. Eur J Gastroenterol Hepatol 2007; 19 (8): 631-638. 